\title{
Evaluating the Low-temperature Properties of Asphalt Binders Extracted from Mixtures Containing Recycled Materials
}

\author{
Eslam Deef-Allah" ${ }^{1 *}$, Magdy Abdelrahman \\ 1 Department of Civil, Architectural and Environmental Engineering, Missouri University of Science and Technology, Rolla, MO \\ 65409, USA \\ * Corresponding author, e-mail: emddkc@mst.edu
}

Received: 10 December 2021, Accepted: 27 February 2022, Published online: 04 March 2022

\begin{abstract}
The use of recycled materials - such as reclaimed asphalt pavement (RAP) and recycled asphalt shingles (RAS) - in asphalt mixtures reduces natural resources demands and decreases materials dumped in landfills. The aged binders included in the recycled materials alter binders' low-temperature properties included in asphalt mixtures. Therefore, asphalt binders were extracted from asphalt mixtures collected from the field as cores. Due to the limited amount of extracted asphalt binders (EABs), a dynamic shear rheometer was used to examine the low-temperature properties [e.g., true temperature $\left(T_{t}\right)$, continuous temperature $\left(T_{c}\right)$, and delta continuous temperature $\left(\Delta T_{c}\right)$ ]. Using recycled materials in asphalt mixtures increased EABs' low temperatures, $T_{t}$ and $T_{c}$, and decreased EABs' $\Delta T_{c}$ values when compared to EABs from mixtures without recycled materials. Using RAS in asphalt mixtures degraded the lowtemperature properties of EABs, $T_{t}$ and $T_{c}$ increased and $\Delta T_{c}$ decreased, when compared to EABs from mixtures containing RAP. Increasing the asphalt binder replacement (ABR) percentages by recycled materials increased $T_{c}$ and decreased $\Delta T_{c}$. The flow activation energy $\left(E_{a}\right)$ was related to the $T_{c}$ and $\Delta T_{c}$ values, and very strong relationships were observed between $E_{a}$ and $T_{c}$ and $E_{a}$ and $\Delta T_{c}$. The researchers modelled two low-temperature prediction models to predict $T_{c}$ and $\Delta T_{c}$ depending on the grade of the virgin asphalt binder, ABR types and percentages, and asphalt mixtures ages.
\end{abstract}

Keywords

recycled materials, low temperature, compliance, flow activation energy, 4-mm plates, delta $T_{c}$

\section{Introduction}

Using recycled materials - such as reclaimed asphalt pavement (RAP) and recycled asphalt shingles (RAS) - in the pavement industry is increasing in the U.S. due to the valuable constituents that make them more appropriate to be used with asphalt mixtures [1-3]. The main issue generated by using RAS in asphalt mixtures is the high stiffness of the asphalt component [4-6]. This asphalt was an oxidized air-blown type, which was stiffer than the asphalt binder included in the RAP [5]. Alavi et al. [2] evaluated the low-temperature performance grades (PGs) of three RAP sources from three plants in California, and it was found to be $-4{ }^{\circ} \mathrm{C}$. Bahia and Swiertz [6] found that blending RAS binder with a fresh binder, PG 58-28, changed the low temperature with $0.4{ }^{\circ} \mathrm{C}$ per one percentage of asphalt binder replacement $(A B R)$.

Delta $T_{c}\left(\Delta T_{c}\right)$ parameter, proposed by Anderson et al. [7], was identified as the difference between the temperature at which the stiffness reached the critical temperature and the temperature at which the relaxation (m-value) reached critical temperature [8]. Good to fair correlations were found between the $\Delta T_{c}$ parameter and mixture cracking testing (e.g., double-edged notch test, Texas overlay tester, and thermal stress restrained specimen test) [8,9]. The AASHTO PP 78 suggested a threshold minimum value for the $\Delta T_{c}$ as $-5{ }^{\circ} \mathrm{C}$ because a significant loss in the resistance to low-temperature cracking occurred below this threshold $[8,10]$. More negative $\Delta T_{c}$ parameter indicated increase cracking susceptibility due to the loss of relaxation properties [8, 11]. McDaniel and Shah [8] found $\Delta T_{c}$ values for the two RAP binders, after $20 \mathrm{~h}$ long-term aging, were $-4{ }^{\circ} \mathrm{C}$ and $-5.5{ }^{\circ} \mathrm{C}$. The researchers did not evaluate the $\Delta T_{c}$ for the RAS binder because it was too stiff to be poured into the bending beam rheometer (BBR) molds [8]. The addition of 2-8\% RAS binder to PG 64-22 virgin asphalt binder (VAB) enhanced the VAB's ability to relax thermal stresses by increasing the $\Delta T_{c}$ parameter [8]. The researchers related 
these findings to the complex interactions between the VAB and RAS binder: There were difficulties in blending the RAS binder and the VAB in the lab [8].

In the transition-state-theory context, the flow activation energy $\left(E_{a}\right)$ is the amount of thermal energy to overcome an energy barrier of asphalt binder's molecules and atoms to move to an adjacent vacant place $[12,13]$. Lower $E_{a}$ indicated that less energy was required to overcome the energy barrier and to cause flow [14]. It was found that the $E_{a}$ depended on the composition of the asphalt binder because asphalt binders with the same PG had different $E_{a}$ values [15]. Moreover, the short- and long-term aging processes increased the $E_{a}$ values [14-16]. During these aging processes, the oxidation increased the number of polar aromatics, and hydrocarbon molecules (asphaltene) that increased the intermolecular forces caused stronger interactions and more resistance to flow $[14,15]$.

The primary objective of this study was to explore the low-temperature properties of extracted asphalt binders (EABs) from mixtures containing different $A B R$ percentages of recycled materials, including different asphalt binders' PGs, and various ages. The EABs' low temperatures properties were related to $E_{a}$ values. Two prediction models were developed for EABs with PG 64-22 VABs and different recycled materials' $A B R$ percentages.

\section{Materials and methods}

\subsection{Materials}

Thirty-one field cores were collected from nine routes in Missouri, U.S.A. These routes were constructed before 2016, and the cores were gathered in 2016 (samples No. 1 to No. 12) and 2019 (samples No. 13 to No. 31). Therefore, EABs were treated as long-term aged binders. The field cores represented nine asphalt mixtures. The asphalt mixtures included different $A B R$ percentages by recycled materials (RAP, RAS, or both). Furthermore, two mixtures contained neither RAP nor RAS (e.g., US 54-7 and MO 94). Details about these cores are presented in Table 1.

\subsection{Methods}

\subsubsection{Extraction and recovery of asphalt binders}

Asphalt binders were extracted from the field cores using the centrifuge extraction process according to ASTM D2172/D2172M-17e1 [17]. Trichloroethylene (TCE) solvent was used in the extraction process. The mineral matter, dust finer than \#200 sieve, was removed from the extracted effluent - asphalt binder dissolved in TCE plus mineral matter - using a filterless centrifuge. Asphalt binders were
Table 1 Details of field cores

\begin{tabular}{|c|c|c|c|c|c|c|}
\hline No. & $\begin{array}{l}\text { Sample } \\
\text { Code }\end{array}$ & Route/Dir & $\begin{array}{c}\text { Virgin } \\
\text { Asphalt } \\
\mathrm{PG}^{\mathrm{a}}\end{array}$ & $\begin{array}{l}\mathrm{AC}^{\mathrm{b}} \\
(\%)\end{array}$ & $\begin{array}{c}\text { ABR by } \\
\text { RAP-RAS } \\
(\%)\end{array}$ & Year $^{\mathrm{c}}$ \\
\hline 1 & US 63-2-F1 & \multirow[t]{3}{*}{ US 63 SB } & \multirow[t]{3}{*}{$64-22$} & \multirow[t]{3}{*}{5.6} & \multirow[t]{3}{*}{$20-10$} & \multirow[t]{3}{*}{2008} \\
\hline 2 & US 63-2-F2 & & & & & \\
\hline 3 & US 63-2-F3 & & & & & \\
\hline 4 & MO 52-1-F1 & \multirow[t]{3}{*}{ MO 52} & \multirow[t]{3}{*}{$64-22$} & \multirow[t]{3}{*}{4.8} & \multirow[t]{3}{*}{$0-34$} & \multirow[t]{3}{*}{2010} \\
\hline 5 & MO 52-1-F2 & & & & & \\
\hline 6 & MO 52-1-F3 & & & & & \\
\hline 7 & US 54-7-F1 & \multirow[t]{3}{*}{ US 54 WB } & \multirow[t]{3}{*}{$64-22$} & \multirow[t]{3}{*}{6.2} & \multirow[t]{3}{*}{$0-0$} & \multirow[t]{3}{*}{2003} \\
\hline 8 & US 54-7-F2 & & & & & \\
\hline 9 & US 54-7-F3 & & & & & \\
\hline 10 & US 54-8-F1 & \multirow[t]{3}{*}{ US 54} & \multirow[t]{3}{*}{$70-22$} & \multirow[t]{3}{*}{5.6} & \multirow[t]{3}{*}{$9-0$} & \multirow[t]{3}{*}{2006} \\
\hline 11 & US 54-8-F2 & & & & & \\
\hline 12 & US 54-8-F3 & & & & & \\
\hline 13 & MO 151-F1 & \multirow[t]{5}{*}{ MO 151} & \multirow[t]{5}{*}{$64-22$} & \multirow[t]{5}{*}{4.7} & \multirow[t]{5}{*}{$16-15$} & \multirow[t]{5}{*}{2014} \\
\hline 14 & MO 151-F2 & & & & & \\
\hline 15 & MO 151-F3 & & & & & \\
\hline 16 & MO 151-F4 & & & & & \\
\hline 17 & MO 151-F5 & & & & & \\
\hline 18 & US 54-F1 & \multirow[t]{3}{*}{ US $54 \mathrm{E}$} & \multirow[t]{3}{*}{$70-22$} & \multirow[t]{3}{*}{5.7} & \multirow[t]{3}{*}{$12-0$} & 2010 \\
\hline 19 & US 54-F2 & & & & & \\
\hline 20 & US 54-F3 & & & & & \\
\hline 21 & MO 6-F1 & MO $6 \mathrm{~W}$ & $58-28$ & 5.9 & $30-0$ & 2015 \\
\hline 22 & MO 6-F2 & & & & & \\
\hline 23 & MO 6-F3 & & & & & \\
\hline 24 & MO 6-F4 & & & & & \\
\hline 25 & MO 6-F5 & & & & & \\
\hline 26 & MO 94-F1 & MO 94 & $64-22$ & 5.6 & $0-0$ & 2005 \\
\hline 27 & MO 94-F2 & & & & & \\
\hline 28 & MO 94-F3 & & & & & \\
\hline 29 & US 36-F1 & US $36 \mathrm{E}$ & $64-22$ & 5.1 & $25-0$ & 2011 \\
\hline 30 & US 36-F2 & & & & & \\
\hline 31 & US 36-F3 & & & & & \\
\hline $\begin{array}{ll}\mathrm{a} & \mathrm{Vi} \\
\mathrm{Fo} \\
\mathrm{b} & \mathrm{To} \\
\text { in } \\
\text { c } & \mathrm{Co}\end{array}$ & $\begin{array}{l}\text { in asphalt pe } \\
\text { nula (JMF). } \\
\text { lasphalt con } \\
\text { e JMF by the } \\
\text { truction yea }\end{array}$ & $\begin{array}{l}\text { nt (AC) afte } \\
\text { contractor. }\end{array}$ & de as indi & tion $\mathrm{p}$ & the Job Mix & sented \\
\hline
\end{tabular}

recovered from the asphalt binder-solvent solutions, after mineral matter removal, using a rotavap. The procedures for implementing this experiment were illustrated in ASTM D5404 / D5404M-21 [18].

\subsubsection{Low-temperature properties of EABs using a dynamic shear rheometer}

There were difficulties in evaluating the low-temperature properties of EABs using the BBR due to the limited amount 
of EABs. Therefore, a dynamic shear rheometer (DSR) was utilized for this purpose. To evaluate the low-temperature properties of EABs by the BBR at three temperatures, at least 33 grams of EAB were required. However, an EAB sample of 0.02265 gram was used in the DSR to characterize its low-temperature properties at various temperatures. To obtain the stiffness $[S(t)]$ and $m$-value, the DSR shear results in a frequency domain were converted to BBR flexural results in a time domain.

Measuring the compliance of the DSR

The DSR's compliance was measured by freezing the upper and lower 4-mm plates together using distilled water at $-40{ }^{\circ} \mathrm{C}$. An oscillation amplitude sweep test was conducted using torque values from 100 to $30000 \mu \mathrm{N}$.m at a frequency of $1 \mathrm{~Hz}(6.28 \mathrm{rad} / \mathrm{s})$ [19]. The slope of the linear relationship between torque in N.m and displacement in m.rad was calculated as the DSR's compliance in m.rad/N.m (Fig. 1). The DSR compliance, $24.068 \mathrm{~m} . \mathrm{rad} / \mathrm{N} . \mathrm{m}$, was used to correct EABs' measurements by inserting this value in the software of DSR.

Frequency sweep test

The EABs were tested using 4-mm diameter and 1.75-mm gap samples through frequency sweep testing. Oscillation frequency sweep tests were utilized at different temperatures $\left(-24,-18,-12,-6,0,6\right.$, and $\left.12{ }^{\circ} \mathrm{C}\right)$. For each temperature, 50.00, 39.81, 25.12, 15.85, 10.00, 6.31, 3.98, 2.51, 1.58, $1.00,0.63,0.39,0.25,0.15$, and $0.10 \mathrm{rad} / \mathrm{s}$ angular frequency values were used [19]. The strain value was $0.001 \%$ to ensure it was obtaining data within the linear viscoelastic (LVE) region. The normal force was kept within $1 \pm 0.1 \mathrm{~N}$ through testing to overcome EAB samples' contractions and adhesion losses between the sample and upper plate.

Converting DSR shear results into BBR flexural results

The master curves were developed from the frequency sweep testing results at the expected low PG temperatures plus ten degrees Celsius. A sigmoidal function in the

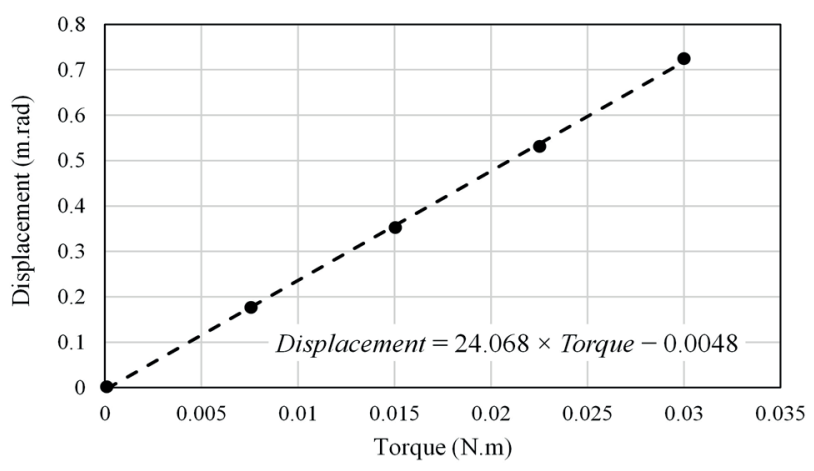

Fig. 1 Relationship between torque and displacement mechanistic-empirical pavement design guide discussed the rate dependency of the dynamic modulus master curve for asphalt mixtures [20, 21]. However, the sigmoidal function was used to evaluate the behaviors of the asphalt binders' master curves [19, 22]. This function is presented in Eq. (1), and it was utilized to predict the elastic $\left(G^{\prime}\right)$ and viscous $\left(G^{\prime \prime}\right)$ moduli at different reduced frequencies $\left(\omega_{r}\right)$ [19]. The elastic modulus $\left(G^{\prime}\right)$ is characterized by the following equation:

$\log \left|G^{\prime}\right|=\delta+\frac{\alpha}{1+e^{\beta+\gamma\left\{\log \left(\omega_{r}\right)\right\}},}$

where $G^{\prime}$ is the elastic modulus, $\omega_{r}$ is the reduced angular frequency, and $\delta, \alpha, \beta$, and $\gamma$ are the fitting parameters ( $\delta$ is the lower asymptote, $\alpha$ is the difference between the lower and upper asymptotes' values, and $\beta$ and $\gamma$ define the shape between the asymptotes and the location of the inflection point $\left(10^{\beta / \gamma}\right)$ [23]).

The shear stress relaxation modulus $[G(t)]$ was obtained from Eq. (2) $[24,25]$. The stiffness $[S(t)]$ was calculated using Eq. (3) [26]. The stiffness and $m$-value for each EAB at the low PG temperature plus ten degrees Celsius were considered at 60 seconds [19]. The following equation characterized the $G(t)$ :

$G(t)=G^{\prime}\left(\omega_{r}\right)-0.4 G^{\prime \prime}\left(0.4 \omega_{r}\right)+0.014 G^{\prime \prime}\left(10 \omega_{r}\right)$.

The stiffness value is calculated by the following equation:

$S(t)=\frac{1}{D(t)}=\frac{2(1+v)}{J(t)}$,

where $D(t)$ is the tension/compression creep compliance, $J(t)$ is the shear creep compliance [the inverse of $G(t)$ ], and $v$ is the Poisson's ratio $(0.35)$.

\subsubsection{Flow activation energy}

The flow activation energy $\left(E_{a}\right)$ was calculated for each EAB using the viscosity-based Arrhenius model (Eq. (4)) [27] and the shift factors-based Arrhenius model (Eq. (5)) [28, 29]. Frequency sweep test was conducted for each EAB, using $25-\mathrm{mm}$ diameter and $1-\mathrm{mm}$ thickness plates, at 58 to $82^{\circ} \mathrm{C}$ with an increment of $6^{\circ} \mathrm{C}$. For each temperature, 100 to $0.01 \mathrm{rad} / \mathrm{s}$ angular frequencies were utilized. The strain value was selected, based on the strain amplitude sweep test results, to ensure the frequency sweep test was conducted at the LVE region. The viscosity-based Arrhenius model is characterized by the following equation: 
$\eta^{*}=A e^{E_{a} / R T}$,

where $\eta^{*}$ is the complex shear viscosity at zero or low shear rate, $0.01 \mathrm{rad} / \mathrm{s}$ [27], in Pa.s, $A$ is a pre-exponential parameter, $E_{a}$ is the flow activation energy in $\mathrm{kJ} \mathrm{mol}^{-1}, R$ is the universal gas constant $\left(0.008314 \mathrm{~kJ} \mathrm{~mol}^{-1} \mathrm{~K}^{-1}\right)$, and $T$ is the temperature in ${ }^{\circ} \mathrm{K}$.

The shift factors-based Arrhenius model is represented by the following equation:

$$
\ln a_{T}=\left(\frac{E_{a}}{R}\right)\left(\frac{1}{T}-\frac{1}{T_{0}}\right),
$$

where $a_{T}$ is the temperature shift factor, $T$ is the temperature in ${ }^{\circ} \mathrm{K}$, and $T_{0}$ is the reference temperature in ${ }^{\circ} \mathrm{K}$.

\section{Results and analysis}

\subsection{Frequency sweep test results}

The frequency sweep test results for the MO 6-F2 EAB are shown in Fig. 2(a). This figure illustrates the $G^{\prime}$ and $G^{\prime \prime}$ measured at 50 to $0.1 \mathrm{rad} / \mathrm{s}$ angular frequencies $(\omega)$ and -24 to $12{ }^{\circ} \mathrm{C}$ temperatures. At the lowest temperatures, -24 ${ }^{\circ} \mathrm{C}$, the difference between the $G^{\prime}$ and $G^{\prime \prime}$ values was the

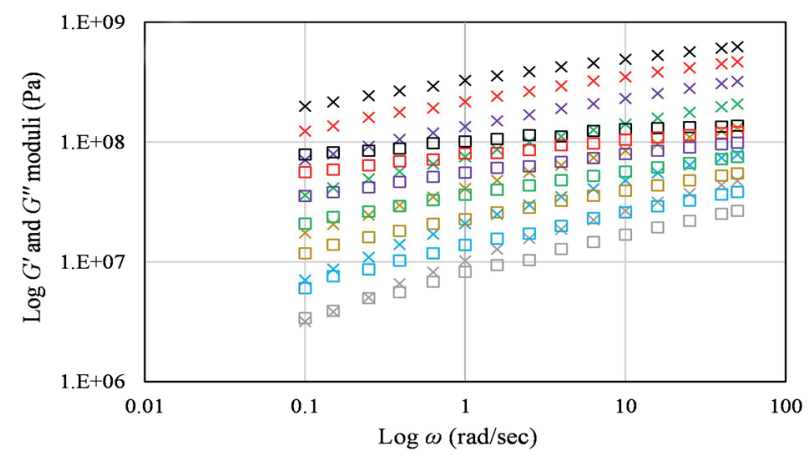

(a)

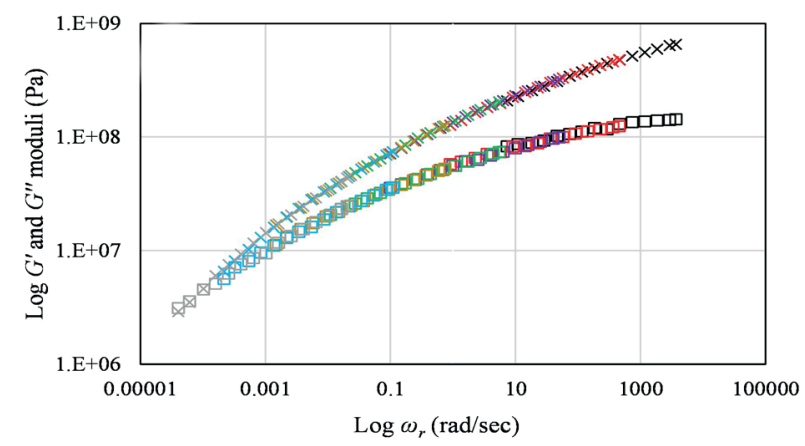

(b)

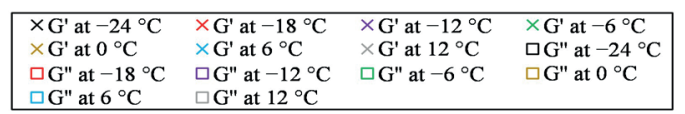

Fig. 2 (a) Frequency sweep test results and (b) Master curve at $-12{ }^{\circ} \mathrm{C}$ for MO 6-F2 EAB highest. Increasing the temperature and decreasing the frequency resulted in a decrease in the difference between the $G^{\prime}$ and $G^{\prime \prime}$ values. The frequency sweep test results were utilized to create the master curve at specific temperatures. Fig. 2(b) depicts the master curve results, $G^{\prime}$ and $G^{\prime \prime}$ versus $\omega_{r}$ in $\log$ scale, at $-12{ }^{\circ} \mathrm{C}\left(-22{ }^{\circ} \mathrm{C}\right.$ low $\mathrm{PG}$ temperature $)$.

\subsection{Calculation of EABs' stiffnesses and $m$-values}

The EABs' stiffness values were calculated at 60 seconds using Eq. (3). The $m$-value was the slope of the tangent line at 60 seconds of the fitted relationship between the log time and $\log S(t)$. Fig. 3 illustrates the $\log$ time versus $\log S(t)$ for the MO 6-F2 EAB measured at $-12{ }^{\circ} \mathrm{C}$. The $S(t)$ and $m$-value were $167.88 \mathrm{MPa}$ and 0.314 , respectively. This depicted that the MO 6- F2 EAB passed $-12{ }^{\circ} \mathrm{C},-22^{\circ} \mathrm{C}$ low PG temperature, because the $\mathrm{S}(\mathrm{t})$ was less than $300 \mathrm{MPa}$ and the $m$-value was greater than 0.3 . The same procedures were followed for the MO 6- F2 EAB at $-18{ }^{\circ} \mathrm{C},-28^{\circ} \mathrm{C}$ low $\mathrm{PG}$ temperature, and the $\mathrm{EAB}$ failed at this temperature because the $S(t)$ was greater than $300 \mathrm{MPa}(310.03 \mathrm{MPa})$ and the $m$-value was less than $0.3(0.264)$. Thus, the low PG temperature of the MO 6- F2 EAB was $-22{ }^{\circ} \mathrm{C}$.

\subsection{True and continuous low temperatures of EABs}

The true $\left(T_{t}\right)$ and continuous $\left(T_{c}\right)$ low temperatures were calculated and presented in Table 2 for EABs. The $T_{c}$ was estimated as the maximum of the $T_{c \text { stiffness }}\left(T_{c, S}\right)$ and $T_{c m \text {-value }}$ $\left(T_{c, m}\right)$. The $T_{c, S}$ and $T_{c, m}$ values were estimated using Eq. (6) and Eq. (7), respectively. The $T_{c, S}$ is represented by the following equation:

$$
T_{c, S}=T_{1}+\frac{\left(T_{1}-T_{2}\right)\left(\log 300-\log S_{1}\right)}{\log S_{1}-\log S_{2}}-10 .
$$

The $T_{c, m}$ is characterized by the following equation:

$$
T_{c, m}=T_{1}+\frac{\left(T_{1}-T_{2}\right)\left(0.3-m_{1}\right)}{m_{1}-m_{2}}-10,
$$

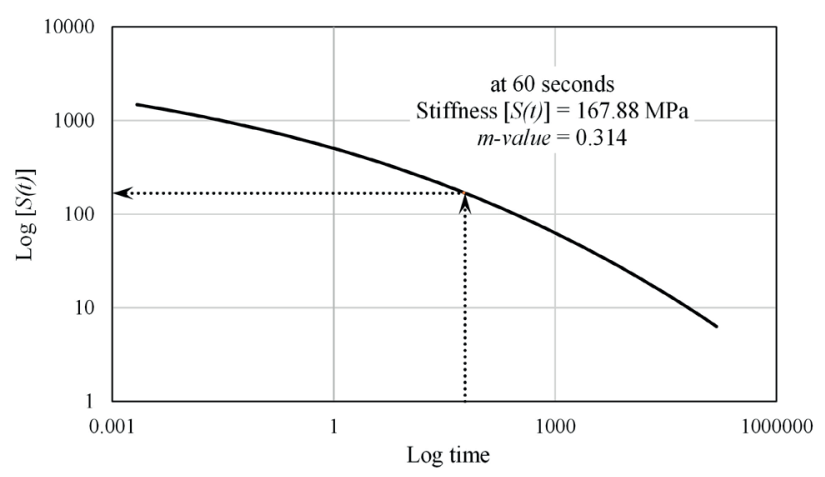

Fig. 3 Stiffness and $m$-value of the MO 6-F2 EAB at $-12{ }^{\circ} \mathrm{C}$ 
Table 2 True and continuous low temperatures of EABs

\begin{tabular}{|c|c|c|c|c|c|}
\hline EAB Code & Mixture Code & $T_{t}\left({ }^{\circ} \mathrm{C}\right)$ & $T_{c, S}\left({ }^{\circ} \mathrm{C}\right)$ & $T_{c, m}\left({ }^{\circ} \mathrm{C}\right)$ & $T_{c}\left({ }^{\circ} \mathrm{C}\right)$ \\
\hline MO 6-F1 & MO 6 & -16 & -27.13 & -21.41 & -21.41 \\
\hline MO 6-F2 & & -22 & -27.68 & -23.68 & -23.68 \\
\hline MO 6-F3 & & -22 & -29.50 & -24.68 & -24.68 \\
\hline MO 6-F4 & & -16 & -27.00 & -21.01 & -21.01 \\
\hline MO 6-F5 & & -16 & -26.41 & -20.26 & -20.26 \\
\hline MO 94-F1 & MO 94 & -16 & -19.37 & -20.67 & -19.37 \\
\hline MO 94-F2 & & -10 & -15.81 & -16.25 & -15.81 \\
\hline MO 94-F3 & & -16 & -18.26 & -17.91 & -17.91 \\
\hline MO 151-F1 & MO 151 & 2 & -7.63 & -4.27 & -4.27 \\
\hline MO 151-F2 & & -4 & -14.96 & -7.37 & -7.37 \\
\hline MO 151-F3 & & 2 & -10.85 & -4.27 & -4.27 \\
\hline MO 151-F4 & & -4 & -14.24 & -4.64 & -4.64 \\
\hline MO 151-F5 & & 2 & -6.99 & -1.13 & -1.13 \\
\hline US 54-F1 & US 54 & -4 & -9.05 & -7.20 & -7.20 \\
\hline US 54-F2 & & -4 & -12.75 & -10.90 & -10.90 \\
\hline US 54-F3 & & -10 & -14.45 & -13.06 & -13.06 \\
\hline US 54-7-F1 & US 54-7 & -22 & -22.46 & -23.62 & -22.46 \\
\hline US 54-7-F2 & & -22 & -25.00 & -25.42 & -25.00 \\
\hline US 54-7-F3 & & -16 & -22.53 & -23.17 & -22.53 \\
\hline US 54-8-F1 & US 54-8 & -16 & -20.65 & -17.22 & -17.22 \\
\hline US 54-8-F2 & & -16 & -21.25 & -20.70 & -20.70 \\
\hline US 54-8-F3 & & -16 & -19.95 & -17.08 & -17.08 \\
\hline US 63-2-F1 & US 63-2 & -4 & -13.36 & -10.47 & -10.47 \\
\hline US 63-2-F2 & & -10 & -19.15 & -13.39 & -13.39 \\
\hline US 63-2-F3 & & -10 & -16.61 & -11.91 & -11.91 \\
\hline MO 52-1-F1 & MO 52-1 & -4 & -20.04 & -4.61 & -4.61 \\
\hline MO 52-1-F2 & & -4 & -20.57 & -7.24 & -7.24 \\
\hline MO 52-1-F3 & & -4 & -18.74 & -6.57 & -6.57 \\
\hline US 36-F1 & US 36 & -10 & -19.58 & -14.58 & -14.58 \\
\hline US 36-F2 & & -16 & -20.71 & -16.88 & -16.88 \\
\hline US 36-F3 & & -10 & -20.24 & -15.18 & -15.18 \\
\hline
\end{tabular}

where $T_{1}$ is the temperature at which $S(t)$ and $m$-value passed, $T_{2}$ is the temperature at which $S(t)$ and $m$-value failed, $S_{1}$ is the $S(t)$ value at $T_{1}, S_{2}$ is the $S(t)$ value at $T_{2}, m_{1}$ is the $m$-value at $T_{1}$, and $m_{2}$ is the $m$-value at $T_{2}$.

Fig. 4 demonstrates the average $T_{c}$ values for EABs from the same asphalt mixtures. The lowest $T_{t}$ and $T_{c}$ values were recorded for the US 54-7 EABs followed by MO 6, US 54-8, MO 94, and then US 36 EABs. The US 54-7 and MO 94 mixtures were respectively 13 and 14 years old during the sampling process. They were the oldest mixtures; however, they did not contain recycled materials. The MO 6 mixture contained the highest $A B R$ percentage by RAP (30\%); however, it included the softest VAB with a PG of $58-28$, and it was 4 years old. The US 54-8 mixture was 10 years old, and it included VAB with a PG of 70-22, nevertheless, it contained $9 \% A B R$ percentage by RAP. The highest $T_{t}$ and $T_{c}$ values were noted for the MO 151 EABs followed by MO 52-1, US 54, and US 63-2 EABs. The MO 151 mixture was 5 years old, and it included $31 \% A B R$ percentage by RAP and RAS. The MO 52-1 mixture was the youngest after the MO 6 mixture; however, it contained $34 \%$ ABR percentage by RAS. This proved that using RAS deteriorated the low-temperature properties of the EABs when compared to EABs from mixtures containing RAP. The US 54 mixture was 9 years old, and it contained VAB with a PG of 70-22; however, it included $12 \% A B R$ percentage by RAP. The US 63-2 mixture was 8 years old and contained $30 \% A B R$ percentage by RAP and RAS. These findings reflected that the grade of the VAB, the $A B R$ percentage by recycled materials, and the mixture's age controlled the low temperature of the EABs.

\subsection{Relationship between $T_{c}$ and $A B R$ percentage}

The relationship between EABs' $T_{c}$ and $A B R$ percentage are depicted in Fig. 5. A very strong polynomial relationship was detected between $T_{c}$ and $A B R$ percentage because

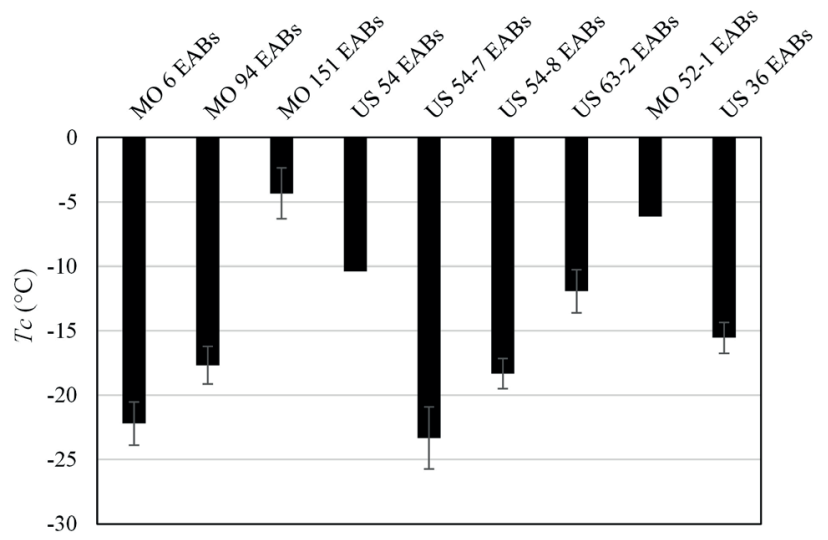

Fig. $4 T_{c}$ values of EABs

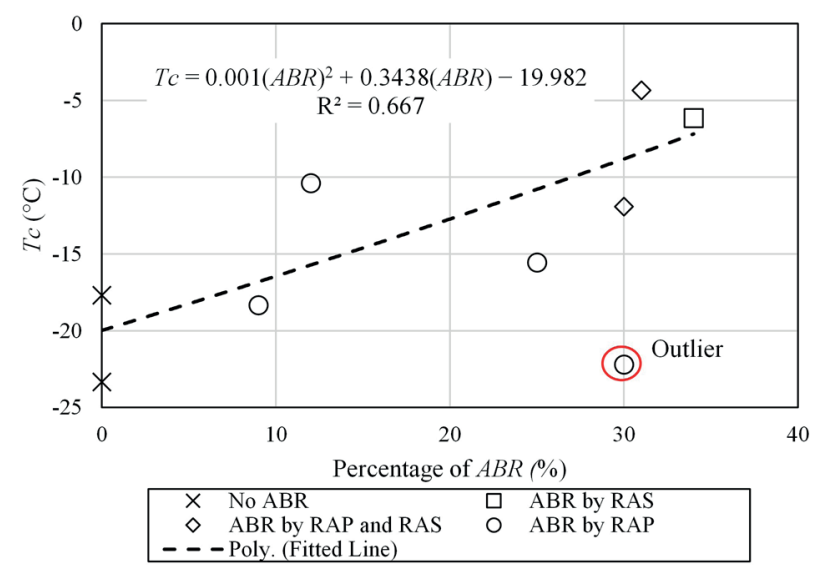

Fig. 5 Relationship between $T_{c}$ and $A B R$ percentage 
the absolute value of the correlation coefficient $(|R|)$ was greater than 0.8 [30]. The lowest $T_{c}$ values were observed for EABs from mixtures without recycled materials followed by EABs from mixture containing 9\% $A B R$ percentage by RAP. The highest $T_{c}$ values were noted for EABs from the mixture containing $31 \% A B R$ percentage by RAP and RAS followed by EAB from the mixture containing $34 \% A B R$ percentage by RAS.

\subsection{Relationship between $\Delta T_{c}$ and $A B R$ percentage}

In this section, the relationship between EABs' $\Delta T_{c}$ and $A B R$ percentage was investigated. The $\Delta T_{c}$ was calculated and averaged for EABs from the same mixture using Eq. (8):

$$
\Delta T_{c}=T_{c, S}-T_{c, m} .
$$

A very strong exponential relationship was deemed in Fig. 6 with $|\mathrm{R}|$ value equal to 0.95 . The highest $\Delta T_{c}$ values, greater than $0.4{ }^{\circ} \mathrm{C}$, were observed for the EABs from mixtures without RAP or RAS (MO 94 and US 54-7); however, these mixtures were the oldest. The lowest $\Delta T_{c}$ value, $-13.65^{\circ} \mathrm{C}$, was noted for the MO 52-1 EAB with 34\% $A B R$ percentage by RAS and followed by EABs from mixtures containing RAP and RAS. For EABs from mixtures containing RAP and RAS, increasing the $A B R$ percentages by RAS decreased the $\Delta T_{c}$ values. The EABs from mixtures containing RAP showed $\Delta T_{c}$ values between -1.70 and $-5.34{ }^{\circ} \mathrm{C}$. Thus, regardless of the age of the asphaltic mixtures, using recycled materials in these mixtures decreased the $\Delta T_{c}$ values for EABs when compared to EABs from mixtures without recycled materials. Additionally, the RAS had the worst effect on the $\Delta T_{c}$ values when compared to the effect of RAP: EABs from mixtures containing RAS had the lowest $\Delta T_{c}$ values followed by mixtures containing RAP and RAS.

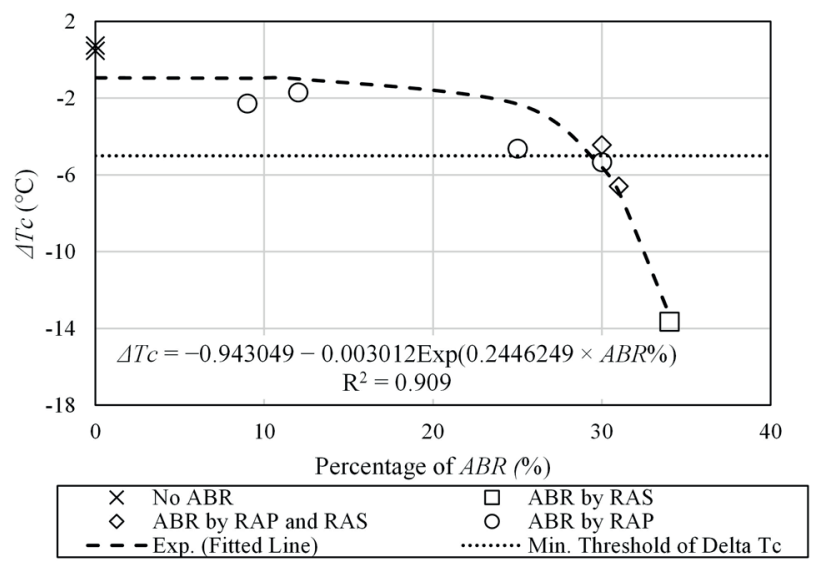

Fig. 6 Relationship between $\Delta T_{c}$ and ABR percentage
From Fig. 6, three types of EABs had $\Delta T_{c}$ values below the minimum threshold $\left(-5^{\circ} \mathrm{C}\right)$. These binders included the highest $A B R$ percentages by RAP, RAS, or RAP and RAS. The EABs with positive $\Delta T_{c}$ values, MO 94 and US 54-7 EABs, were S-controlled binders. The S-controlled binders failed the stiffness limit, $300 \mathrm{MPa}$, at a temperature warmer than the temperature of the m-value [31]. However, the remaining binders with negative $\Delta T_{c}$ values were m-controlled binders. The m-controlled binders failed the $m$-value threshold of 0.3 at a temperature warmer than the stiffness temperature [31]. It was found that the m-controlled binders exhibited lower thermal stress resistance [32, 33].

\subsection{Relationships between $E_{a}$ and low-temperature properties}

The $E_{a}$ values for each EAB using the viscosity-based and shift factor-based Arrhenius model are illustrated in Table 3. The lowest $E_{a}$ values were recorded for EABs from mixtures without recycled materials and followed by EABs from mixtures containing RAP. The highest $E_{a}$ values were noted for EABs from mixtures containing RAP and RAS and were followed by EABs from a mixture including RAS. Relationships between $T_{c}$ and $E_{a}$ and between $\Delta T_{c}$ and $E_{a}$ were established and analyzed in Fig. 7 and Fig. 8, respectively. Very strong exponential relationships were observed in both figures with $|\mathrm{R}|$ values greater than or equal to 0.8 . The relationship between $\Delta T_{c}$ and $E_{a}$ (Fig. 8) was stronger than the relationship between $T_{c}$ and $E_{a}$ (Fig. 7).

\subsection{Fitting models to characterize the low-temperature properties}

Based on this study, the low-temperature properties, $T_{c}$ and $\Delta T_{c}$, mainly depended on the mixtures' ages, the VABs' grades, recycled material types, and $A B R$ percentages by recycled materials. Two models were fitted in this section; the first one characterized the $T_{c}$ and the second one described the $\Delta T_{c}$. The fitted models were based on 20 EABs from 6 mixtures with PG 64-22 VABs. The mixtures included RAP, RAS, both, or none.

\subsection{1 $T_{c}$ prediction model}

The $T_{c}$ values of EABs were predicted using Eq. (9) by knowing the mixtures' ages, recycled material types, and $A B R$ percentages by recycled materials. Fig. 9 demonstrates a very strong relationship between the actual and the predicted $T_{c}$ values. The following equation characterized the $T_{c}$ values for EABs: 


$$
\begin{aligned}
T_{c} & =-60.66583243+7.0071334803 \times A g e \\
& +(A B R-21.1) \times \mu,
\end{aligned}
$$

where $T_{c}$ is the continuous low temperature of EAB, $A g e$ is the age of mixture, $A B R$ is the percentage of asphalt binder replacement by recycled materials. It should be greater than or equal to $25 \%$, and $\mu$ is a factor that depends on the type of $A B R$ by recycled materials (2.5800289056 for zero $A B R$, -2.81899816 for $A B R$ by RAP, -0.727390718 for $A B R$ by RAP and RAS, and 0.9663599725 for $A B R$ by RAS).

\begin{tabular}{|c|c|c|c|}
\hline \multirow[b]{2}{*}{ EAB Code } & \multicolumn{3}{|c|}{$E_{a}(\mathrm{~kJ} / \mathrm{mol})$} \\
\hline & Mixture Code & $\begin{array}{l}\text { Based on the zero- } \\
\text { shear viscosity }\end{array}$ & $\begin{array}{l}\text { Based on the } \\
\text { shift factors }\end{array}$ \\
\hline MO 6-F1 & MO 6 & 159.63 & 158.47 \\
\hline MO 6-F2 & & 156.63 & 161.28 \\
\hline MO 6-F3 & & 151.52 & 154.18 \\
\hline MO 6-F4 & & 161.19 & 161.53 \\
\hline MO 6-F5 & & 162.26 & 162.78 \\
\hline MO 94-F1 & MO 94 & 145.22 & 147.33 \\
\hline MO 94-F2 & & 149.66 & 154.10 \\
\hline MO 94-F3 & & 149.54 & 151.36 \\
\hline MO 151-F1 & MO 151 & 175.22 & 179.79 \\
\hline MO 151-F2 & & 173.41 & 169.82 \\
\hline MO 151-F3 & & 166.95 & 172.47 \\
\hline MO 151-F4 & & 168.80 & 172.20 \\
\hline MO 151-F5 & & 180.89 & 185.71 \\
\hline US 54-F1 & US 54 & 165.90 & 167.09 \\
\hline US 54-F2 & & 159.48 & 159.18 \\
\hline US 54-F3 & & 149.27 & 153.55 \\
\hline US 54-7-F1 & US 54-7 & 152.26 & 154.35 \\
\hline US 54-7-F2 & & 147.23 & 154.39 \\
\hline US 54-7-F3 & & 151.49 & 157.48 \\
\hline US 54-8-F1 & US 54-8 & 153.07 & 155.21 \\
\hline US 54-8-F2 & & 148.85 & 151.90 \\
\hline US 54-8-F3 & & 153.85 & 152.71 \\
\hline US 63-2-F1 & US 63-2 & 168.54 & 165.28 \\
\hline US 63-2-F2 & & 168.18 & 168.68 \\
\hline US 63-2-F3 & & 168.54 & 165.28 \\
\hline MO 52-1-F1 & MO 52-1 & 165.46 & 171.02 \\
\hline MO 52-1-F2 & & 164.88 & 166.69 \\
\hline MO 52-1-F3 & & 162.30 & 171.96 \\
\hline US 36-F1 & US 36 & 165.75 & 169.35 \\
\hline US 36-F2 & & 164.82 & 164.57 \\
\hline US 36-F3 & & 165.88 & 162.16 \\
\hline
\end{tabular}

Table 3 Flow activation energy values for EABs

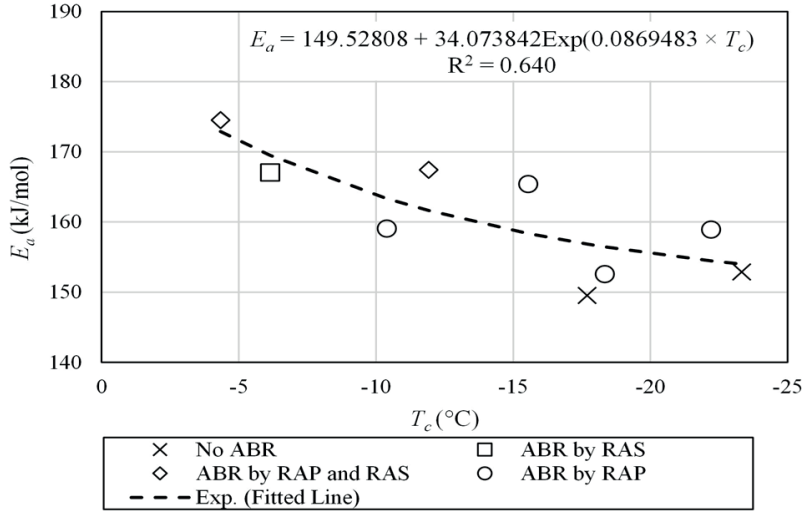

Fig. 7 Relationship between $T_{c}$ and $E_{a}$

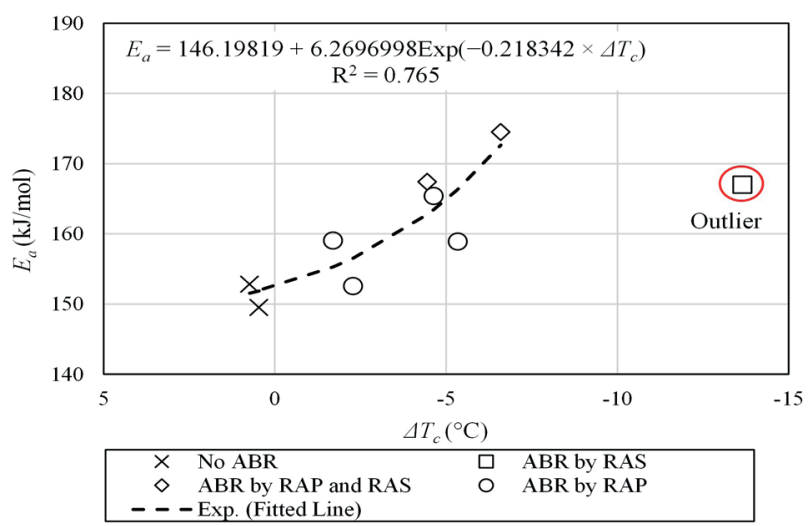

Fig. 8 Relationship between $\Delta T_{c}$ and $E_{a}$

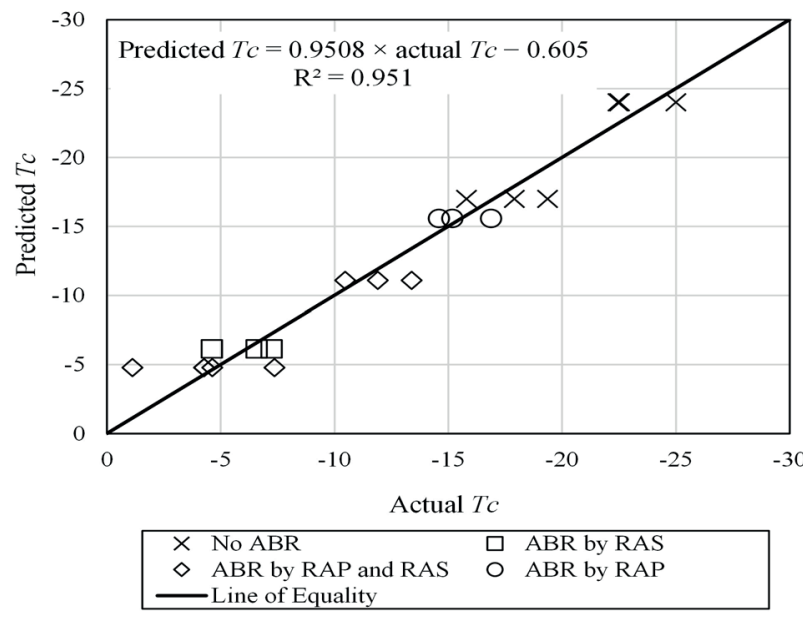

Fig. 9 Actual versus predicted $T_{c}$

\subsubsection{Delta $T_{c}$ prediction model}

The $\Delta T_{c}$ values of EABs were predicted using Eq. (10). Fig. 10 depicts a very strong relationship between the actual and the predicted $\Delta T_{c}$ values. The highest $\Delta T_{c}$ values were observed for EABs from mixtures without recycled materials; however, the EABs from mixtures containing RAS had the lowest $\Delta T_{c}$ values. The following equation characterized the $\Delta T_{c}$ values for EABs: 


$$
\begin{aligned}
\Delta T_{c} & =2.8357241101-1.430810768 \times A g e \\
& +(A B R-21.1) \times \mu,
\end{aligned}
$$

where $\Delta T_{c}$ is the delta continuous low temperature of $\mathrm{EAB}$, Age is the age of mixture, $A B R$ is the percentage of asphalt binder replacement by recycled materials. It should be greater than or equal to $25 \%$, and $\mu$ is a factor that depends on the type of $A B R$ by recycled materials (-0.809202214 for zero $A B R, 1.0328823464$ for $A B R$ by RAP, 0.3876768713 for $A B R$ by RAP and RAS, and -0.611357004 for $A B R$ by RAS).

\section{Conclusions}

This study focused on exploring the low-temperature properties of extracted asphalt binders (EABs) from 31 field cores, representing 9 asphaltic mixtures, containing different virgin asphalt binders (VABs), including different types and percentages of asphalt binder replacement $(A B R)$ by recycled materials, and being different ages. Asphalt mixtures contained different percentages of $A B R$ by reclaimed asphalt pavement (RAP), recycled asphalt shingles (RAS), both, or none. The low-temperature

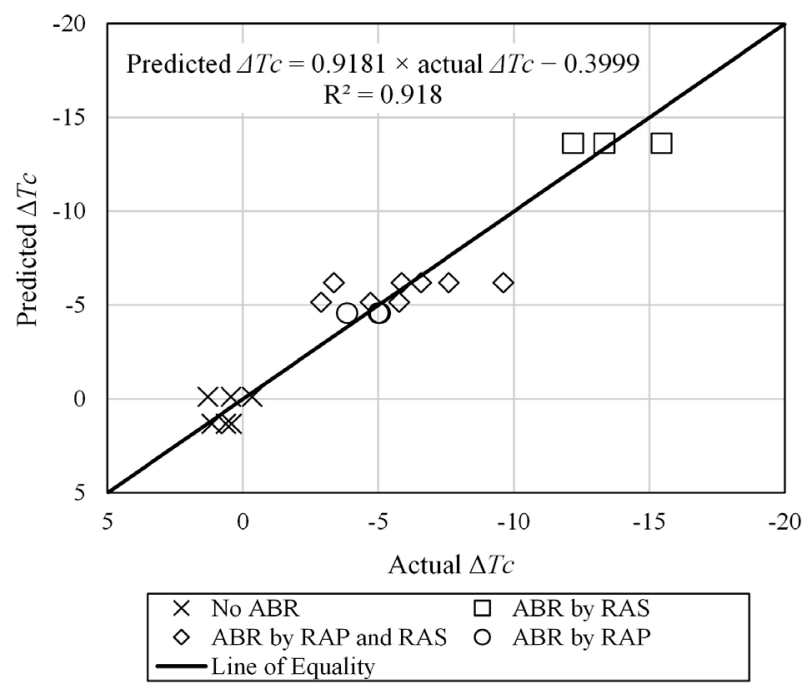

Fig. 10 Actual versus predicted $\Delta T_{c}$

\section{References}

[1] Gonzalez, C., Jersey, S. "Construction and field performance of hot mix asphalt with moderate and high RAP contents", In: Bearing Capacity of Roads, Railways and Airfields - Proceedings of the 8th International Conference on the Bearing Capacity of Roads, Railways and Airfields, Champaign, IL, USA, 2009, pp. 32-38.

[2] Alavi, M. Z., Jones, D., He, Y., Chavez, P., Liang, Y. "Investigation of the Effect of Reclaimed Asphalt Pavement and Reclaimed Asphalt Shingles on the Performance Properties of Asphalt Binders: Phase 1 Laboratory Testing", University of California Pavement Research Center, Davis, CA, USA, Rep. UCPRC-RR-2016-06, 2016. properties of EABs were investigated using a dynamic shear rheometer by measuring true low temperatures $\left(T_{t}\right)$, continuous low temperatures $\left(T_{c}\right)$, and delta $T_{c}\left(\Delta T_{c}\right)$. The different relationships between $A B R$ percentages and $T_{c}$ values, $A B R$ percentages and $\Delta T_{c}$, flow activation energy $\left(E_{a}\right)$ and $T_{c}$, and between $E_{a}$ and $\Delta T_{c}$ were explored. Finally, two models were proposed to predict the $T_{c}$ and $\Delta T_{c}$ values of EABs from mixtures containing PG 64-22 VABs, including different $A B R$ types and percentages, and being different ages. This study dictated the following conclusions:

- The use of recycled materials in asphalt mixtures undermined the low-temperature properties increased the $T_{t}$ and $T_{c}$ values and decreased the $\Delta T_{c}$ - of EABs when compared to EABs from mixtures without recycled materials.

- The use of RAS degraded the low-temperature properties of EABs when compared to EABs from mixtures containing RAP.

- A very strong polynomial relationship was revealed between the $T_{c}$ values of EABs and $A B R$ percentages. Increasing $A B R$ percentages by recycled materials increased the $T_{c}$ values.

- A very strong exponential relationship was observed between the $\Delta T_{c}$ values of EABs and $A B R$ percentages. Increasing the percentages of $A B R$ with recycled materials decreased the $\Delta T_{c}$ values.

- Very strong exponential relationships were found between the $E_{a}$ and $T_{c}$ or $\Delta T_{c}$ values of EABs.

- The researchers constructed two prediction models to characterize $T_{c}$ and $\Delta T_{c}$ for EABs. These models were based on the grade of VABs, types and percentages of $A B R$ by recycled materials, and ages of the mixtures.

\section{Acknowledgement}

The authors appreciate Missouri Department of Transportation (MoDOT) for providing them with the funds, field mixtures, and information for this study.

[3] Deef-Allah, E., Abdelrahman, M. "Investigating the relationship between the fatigue cracking resistance and thermal characteristics of asphalt binders extracted from field mixes containing recycled materials", Transportation Engineering, 4, Article number: $100055,2021$.

https://doi.org/10.1016/j.treng.2021.100055

[4] Wang, H., Rath, P., Buttlar, W. G. "Recycled asphalt shingle modified asphalt mixture design and performance evaluation", Journal of Traffic and Transportation Engineering, 7(2), pp. 205-214, 2020. https://doi.org/10.1016/j.jtte.2019.09.004 
[5] Alvergue, A. "Laboratory evaluation of asphalt mixtures and binders with reclaimed asphalt shingle prepared using the wet process", [pdf] MSc Thesis, Louisiana State University and Agricultural and Mechanical College, 2014. Available at: https://digitalcommons.lsu. edu/cgi/viewcontent.cgi?article $=2204 \&$ context $=$ gradschool_theses

[6] Bahia, H. U., Swiertz, D. "Design system for HMA containing a high percentage of RAS material", University of Wisconsin-Madison, Madison, WI, USA, Final report for RMRC project 66, 2011.

[7] Anderson, R. M., King, G. N., Hanson, D. I., Blankenship, P. B. "Evaluation of the relationship between asphalt binder properties and non-load related cracking", Journal of the Association of Asphalt Paving Technologists, 80, pp. 615-664, 2011.

[8] McDaniel, R. S., Shah, A. "Investigation of delta Tc for implementation in Indiana", Joint Transportation Research Program, West Lafayette, IN, USA, Rep. FHWA/IN/JTRP-2019/14, 2020. https://doi.org/10.5703/1288284316923

[9] Mensching, D. J., Rowe, G. M., Daniel, J. S., Bennert, T. "Exploring low-temperature performance in black space", Road Materials and Pavement Design, 16(sup2), pp. 230-253, 2015. https://doi.org/10.1080/14680629.2015.1077015

[10] Christensen, D., Mensching, D., Rowe, G., Anderson, R. M., Hanz,A., Reinke, G., Anderson, D. "Past, present, and future of asphalt binder rheological parameters - Synopsis of 2017 Technical Session 307 at the 96th Annual Meeting of the Transportation Research Board", [pdf] Transportation Research Board, Washington, DC, USA, Rep. E-C241, 2019. Available at: https://onlinepubs.trb.org/onlinepubs/ circulars/ec241.pdf

[11] Coleri, E., Sreedhar, S., Obaid, I. A. "Development of a balanced mix design method in Oregon, Final Report SPR 801", [pdf] Oregon State University, Corvallis, OR, USA, Rep. FHWA-OR-RD-21-03, 2020. Available at: https://www.oregon.gov/odot/Programs/Research Documents/SPR801_Balanced_Mix_Design.pdf

[12] Notani, M. A., Arabzadeh, A., Satvati, S., Tabesh, M. T., Hashjin, N. G., Estakhri, S., Alizadeh, M. "Investigating the high-temperature performance and activation energy of carbon black-modified asphalt binder", SN Applied Sciences, 2, Article number: 303, 2020. https://doi.org/10.1007/s42452-020-2102-z

[13] Caputo, P., Calandra, P., Vaiana, R., Gallelli, V., de Filpo, G., Oliviero Rossi, C. "Preparation of asphalt concretes by gyratory compactor: a case of study with rheological and mechanical aspects", Applied Sciences, 10(23), Article number: 8567, 2020. https://doi.org/10.3390/app10238567

[14] Jamshidi, A., Hamzah, M. O., Shahadan, Z., Yahaya, A. S. "Evaluation of the rheological properties and activation energy of virgin and recovered asphalt binder blends", Journal of Materials in Civil Engineering, 27(3), Article number: 04014135, 2015. https://doi.org/10.1061/(ASCE)MT.1943-5533.0001024

[15] Salomon, D., Zhai, H. "Ranking asphalt binders by activation energy for flow", Journal of Applied Asphalt Binder Technology, 2(2), pp. 52-60, 2002. [online] Available at: http://citeseerx.ist.psu.edu/ viewdoc/summary?doi=10.1.1.500.4596

[16] Zhang, D., Birgisson, B., Luo, X., Onifade, I. "A new short-term aging model for asphalt binders based on rheological activation energy", Materials and Structures, 52(68), Article number: 68, 2019. https://doi.org/10.1617/s11527-019-1364-7
[17] ASTM "ASTM D2172/D2172M-17e1 Standard Test Methods for Quantitative Extraction of Asphalt Binder from Asphalt Mixtures", ASTM International, West Conshohocken, PA, USA, 2018. https://doi.org/10.1520/D2172_D2172M-17E01

[18] ASTM "ASTM D5404/D5404M-21 Standard Practice for Recovery of Asphalt Binder from Solution Using the Rotary Evaporator", ASTM International, West Conshohocken, PA, USA, 2018. https://doi.org/10.1520/D5404_D5404M-21

[19] Hajj, R., Filonzi, A., Rahman, S., Bhasin, A. "Considerations for using the $4 \mathrm{~mm}$ plate geometry in the dynamic shear rheometer for low temperature evaluation of asphalt binders", Transportation Research Record, 2673(11), pp. 649-659, 2019. https://doi.org/10.1177/0361198119855332

[20] Bonaquist, R., Christensen, D. W. "Practical procedure for developing dynamic modulus master curves for pavement structural design", Transportation Research Record, 1929(1), pp. 208-217, 2005. https://doi.org/10.1177/0361198105192900125

[21] ARA, Inc., ERES Division "Guide for Mechanistic-Empirical Design of New and Rehabilitated PStructures", NCHRP, Transportation Research Board, Washington, DC, USA, 2004. [online] Available at: https://onlinepubs.trb.org/onlinepubs/archive/mepdg/2appendices_rr.pdf [Accessed: 20 October 2021]

[22] Md. Yusoff, N. I., Jakarni, F. M., Nguyen, V. H., Hainin, M. R., Airey, G. D. "Modelling the rheological properties of bituminous binders using mathematical equations", Construction and Building Materials, 40, pp. 174-188, 2013.

https://doi.org/10.1016/j.conbuildmat.2012.09.105

[23] Rowe, G., Baumgardner, G., Sharrock, M. "Functional forms for master curve analysis of bituminous materials", In: Loizos, A., Partl, M., Scapas, T., and Al-Qadi, I. (eds.) Advanced Testing and Characterization of Bituminous Materials, CRC Press, London, UK, 2009, pp. 81-91.

[24] Ninomiya, K., Ferry, J. D. "Some approximate equations useful in the phenomenological treatment of linear viscoelastic data", Journal of Colloid Science, 14(1), pp. 36-48, 1959. https://doi.org/10.1016/0095-8522(59)90067-4

[25] Sui, C., Farrar, M. J., Harnsberger, P. M., Tuminello, W. H., Turner, T. F. "New low-temperature performance-grading method", Transportation Research Record, 2207(1), pp. 43-48, 2011. https://doi.org/10.3141/2207-06

[26] Zeng, Z., Underwood, B. S., Castorena, C. "Low-temperature performance grade characterisation of asphalt binder using the dynamic shear rheometer", International Journal of Pavement Engineering, 23(3), pp. 811-823, 2020. https://doi.org/10.1080/10298436.2020.1774766

[27] Wang, H., Liu, X., Apostolidis, P., Scarpas, T. "Rheological behavior and its chemical interpretation of crumb rubber modified asphalt containing warm-mix additives", Transportation Research Record, 2672(28), pp. 337-348, 2018. https://doi.org/10.1177/0361198118781376

[28] Ait-Kadi, A., Brahimi, B., Bousmina, M. "Polymer blends for enhanced asphalt binders", Polymer Engineering \& Science, 36(12), pp. 1724-1733, 1996. https://doi.org/10.1002/pen.10568 
[29] Partal, P., Martínez-Boza, F., Conde, B., Gallegos, C. "Rheological characterisation of synthetic binders and unmodified bitumens", Fuel, 78(1), pp. 1-10, 1999. https://doi.org/10.1016/S0016-2361(98)00121-5

[30] Cooksey, R. W. "Illustrating statistical procedures: finding meaning in quantitative data", Springer Nature Singapore, Singapore, 2020 https://doi.org/10.1007/978-981-15-2537-7

[31] Asphalt Institute Technical Advisory Committee "Use of the delta Tc parameter to characterize asphalt binder behavior", Asphalt Institute, Lexington, KY, USA, IS-240, 2019. [online] Available at: https:// www.asphaltinstitute.org/engineering/delta-tc-technical-documents/
[32] Rodezno, C., Moraes, R., Yin, F., Fortunatus, M. "Recycled asphalt binder study", National Center for Asphalt Technology at Auburn University, Auburn, AL, USA, Rep. WHRP 0092-19-04, 2021.

[33] Chen, X., Wang, J., Zhang, X., Liu, H., Tong, J., Zhao, R. "Evaluating the physical and rheological properties of rejuvenated styrene-butadiene-styrene-modified asphalt binders", Advances in Materials Science and Engineering, 2020, Article ID 4513824, 2020. https://doi.org/10.1155/2020/4513824 